
Gedruckt mit Unterstützung des

Förderungs- und Beihilfefonds Wissenschaft der VG Wort und des

Deutschen Akademischen Austauschdienstes (DAAD) 
Mohamed-Moain Sadek - Die mamlukische Architektur 
ISLAMKUNDLICHE UNTERSUCHUNGEN · BAND 144

\author{
begründet \\ von \\ Klaus Schwarz \\ herausgegeben \\ von \\ Gerd Winkelhane
}


ISLAMKUNDLICHE UNTERSUCHUNGEN · BAND 144

\section{Mohamed-Moain Sadek}

\section{Die mamlukische Architektur der Stadt Gaza}




\section{CIP-Titelaufnahme der Deutschen Bibliothek}

\section{Sadek, Mohamed-Moain:}

Die mamlukische Architektur der Stadt Gaza / MohamedMoain Sadek. - Berlin : Schwarz, 1991

(Islamkundliche Untersuchungen ; Bd. 144)

Zugl.: Berlin, Freie Univ., Diss., 1990

ISBN 3-922968-76-7

NE: GT

Alle Rechte vorbehalten.

Ohne ausdrückliche Genehmigung des Verlages

ist es nicht gestattet, das Werk oder einzelne Teile daraus

nachzudrucken oder zu vervielfältigen.

(c) Gerd Winkelhane, Berlin 1991.

Klaus Schwarz Verlag, Bergstraße 2, 1000 Berlin 41

ISBN 3-922968-76-7 X

Druck: Offsetdruckerei Gerhard Weinert GmbH, D-1000 Berlin 42 
Meiner Mutter

Meinem verstorbenen Vater

Meinem ehemaligen Dozenten, Herrn Dr. Mostafa Nageeb, in Dankbarkeit 